whole of the nucleus, whence it diffuses out into the cytoplasm.

Messurements of the size of cell nuclei of mouse liver showed that diethanolamine administration increases their size; that is, the number of small and medium-sized nuclei diminish and large nuclei appear in a greater quantity (Fig. 2). No mitoses could be detected in the cells of the enlarged livers.

It is suggested that the action of diethanolamine on mouse liver may manifest itself to a large extent in a change of the phospholipid pattern of the cell nuclei. This view is supported by the observations of Artom et al., who showed that by prolonged administration of diethanolamine, choline is partly replaced in the lecithins by diethanolamine, and by the work of H. H. Williams et al.4, who concluded from their experiments carried out on rat hepatoma, produced by feeding butter-yellow, that "the pathological derangement of the phospholipid content of the liver cell occurs primarily in the nucleus".

We are indebted to A. Fajer for carrying out the analytical work.

E. AnnaU

A. Manginelili

Fundação Andréa e Virginia Matarazzo,

Faculdade de Medicina,

Universidade de São Paulo. May 11.

${ }^{1}$ Artom, C., Cornatzer, W. E., and Crowder, M., J. Biol. Chem., 180, 495 (19̈49).

2 Greenstein, J. P., J. Nat. Cancer Inst, 2, 551 (1942).

${ }^{3}$ Fiske and Subba Row, J. Biol. Chem., 66, 375 (1925).

'W illiams, H. H.. Kaucher, M., Richards. A. J., Moyer, E. Z., and Sharpless, G. R. J., J. Biol.' Chem., 160, 227 "(1945).

\section{APPLICATIONS OF ISOTOPES IN SCIENTIFIC RESEARCH}

A

CONFERENCE on the "Applications of Isotopes in Scientific Research" took place in the University of Melbourne during August 14-17 under the auspices of the Chemistry Department of the University and the Commonwealth Scientific and Industrial Research Organization. The eighteen papers presented fell roughly into two main groups: those of a general character dealing with methods of assay, health hazards and limitations of the use of isotopes; and papers that were essentially reports of work in progress.

F. K. McTaggart and I. E. Newnham illustrated the use of zirconium-95 and hafnium-181 as tracers in the study of chemical methods of separating the elements zirconium and hafnium, and presented some new solubility data for the salts of these two metals. Physico-chemical limitations of the tracer technique were considered by Dr. G. M. Harris. In a discussion of the exchange of carbonate ion (containing carbon14) with carbonato-tetrammine cobaltic ion, it was pointed out that any attempt to describe quantitatively the kinetics of the reaction must take into account the isotope effect.

Many instances of variations in the relative abundance of stable isotopes of the lighter elements have been observed. In his paper on the assay of stable isotopes, Dr. J. D. Morrison added to the list of such variations that of the carbon-12/carbon-13 ratio (from 88 to 93 ) in Australian natural graphites.

By means of numerous radioautographs C. $R$. Millikan illustrated the use of manganese-54 to study the distribution of manganese in diseased and healthy plants. Anisotropy of the rate of the self-diffusion of tin in tetragonal single crystals of high purity, disclosed by the use of tin-113 as tracer, was reported by Dr. W. Boss and P. J. Fensham. In polycrystalline tin it was found that the rate of diffusion along grain boundaries is generelly considerably higher than that of volume diffusion except when the boundary is that between crystals of similar orientations or between twins. The effects of structural factors and solvent on the ability of internal cobalt (II) complexes to exchange with cobalt II ions were considered by B. O. West in a paper on "Exchange Reactions and Problems of Chemical Structure".

Illustrating entomological applications of radioactive tracers, Dr. M. F. Day outlined experiments in which methionine containing radiosulphur was fed to clothes moth larvæ. A wide difference between the mechanism of sulphur metabolism in this insect and in some other species is indicated. The results of investigations of the mechanism of reactions in liquid sulphur dioxide by the use of oxygen-18 were discussed by Dr. I. Lauder. Difficulties encountered in the synthesis of isotopic molecules containing deuterium were fully illustrated in F. I. Andersen's account of the preparation of monodeuterio methyl bromide.

Other papers read at the conference were concerned with the fundamentals of nuclear physics (Dr. J. C. Bower), statistics of radioactivity (E. A. Cornish), assay of radioisotopes (Dr. T. H. Oddie), applications of nuclear emulsions (Dr. V. D. Hopper), tracer method limitations in biology (Dr. W. P. Rogers), health and safety precautions (D. J. Stevens), attempts to concentrate potassium-40 (Dr. G. A. Elliott), assay of radioactive minerals ( $\mathrm{J}$. Daly), and general problems in the synthesis of labelled molecules (A. M. Downes). It is hoped that the full report will be available at an early date.

D. P. MELLOR

\section{NATURAL PRODUCTS OF THE BRITISH COLONIES TWO NEW JOURNALS}

$T$ HE functions of the Imperial Institute, at Exhibition Road, London, S.W.7, have recently been reorganised, and two of its former Departments-Mineral Resources, and Plant and Animal Products-have now become, respectively, the Mineral Resources Division of the Colonial Geological Survey, and the Colonial Products Advisory Bureau. Previously, the work of these two Departments was published in the Bulletin of the Imperial Institute; the Bulletin is now replaced by two separate quarterly journals : Colonial Plant and Animal Products', and Colonial Geology and Mineral Resources ${ }^{2}$.

The issue of the first number of the former periodical is of particular significance at the present time when the public conscience has awakened to the pressing needs of the Colonies. As the former Secretary of State for the Colonies, Mr. A. Creech Jones, states in a foreword, the resources of the dependent territories are of increasing importance both to the inhabitants themselves, who demand a higher standard of living, and to the whole of the sterling area. Much was done in the years between the two World Wars and also, let it not be forgotten, in the period before the First World War, to assess the economic potentialities of these territories. But 
during that time the workers were all too few, and with the best will in the world they could touch only the fringe of the work. As is well known, the aftermath of the Second World War has led to profound changes, not only territorially but also financially, due to difficulties that have arisen through currency restrictions. Inevitably attention in Great Britain has been directed to the vast and largely unassessed potentialities of the Colonies, which, being within the sterling area, afford wonderful opportunities for mutual trade to the benefit of both the mother country and the dependencies.

Previously much of this work was carried on by the Imperial Institute and other bodies working independently, and the former Bulletin of the Institute was regarded by most scientific workers in the tropics as a valuable work of reference on natural products. As regards the agricultural research work done at the Imperial Institute laboratories, this was valuable to investigators in the tropics, as it helped them to assess the commercial possibilities of products arising from little-known plants. With the assistance so provided, the worker in the Colonies was able to guide his further researches, if the prospects seemed good, for the development of a profitable market, or to turn his attention to more profitable lines of work if the reports should be unfavourable. A reference to files of agricultural departmental reports will provide numerous examples of the work done in this connexion. The assessment of new types of oil from little-known plants is one example; another is the evaluation of different kinds of fibre obtained from plants that were not hitherto considered to have commercial potentialities; and a third concerns plants of medicinal value. For example, the establishment of the tung oil industry in countries such as Nyasaland, and the development of jute fibre substitutes such as ramie and hibiscus owe much to the pioneer work of the Institute.

Now, with the pressing needs of the times, all this work has, of necessity, been brought under the central direction of the Colonial Products Advisory Bureau, and Colonial Plant and Animal Products indicates that the continuity of these investigations is assured under the new organisation. The first issue reports, for example, on two little-known oil seeds, namely, Lippia carviodora from Kenya, and Hibiscus esculentis, which was always regarded hitherto as a somewhat uninspiring vegetable. Reports on manila hemp in Borneo, and the suitability of banana trash for paper-making, carry on the traditions of the old Fibre Section, and a note on wormseed (Santonica) continues the pharmaceutical tradition. There are three original articles : sugar cane processing; the insect fauna of Lonchocarpus and derris (for, curiously enough, these insecticidal plants are themselves subject to attack by various beetles when their dried roots are in storage); and a note on the preparation of silk gut.

Finally, one is glad to see that the bibliography for agricultural and forestry subjects is continued, as it adds greatly to the value of the journal. Under its new form it is believed that this publication will help to stimulate still further the interest of all interested in Colonial development.

The purpose of the other new journal, Colonial Geology and Mineral Resources, is to record the progress that is being made in the geological investigation of the various territories comprising the Colonial Empire and to provide information of current developments in mineral resources, mining and mineral economics. The first number appropriately contains an authoritative account, by Dr. F. Dixey, of the scope and work of the Directorate of the Colonial Geological Surveys. The primary purpose of the Surveys is the preparation of a basic geological map of the Colonial Empire to serve as the foundation for a thorough investigation of mineral resources. Since the time when the Directorate was established in January 1947, many of the old Surveys have been expanded and plans for new ones have been approved, the territories in which work is now actively in progress being Ugande, Kenya, Tanganyika, Northern Rhodesia, Nyasaland, Bechuanaland, Swaziland, Nigeria, Gold Coast, Sierra Leone, Malaya, Sarawak and North Borneo, Fiji, British Guiana, Jamaica and Cyprus. The overseas and London staffs num. bered 111 and 25, respectively, in April 1950 and are expected to reach 160 and 45 by the end of next year.

The journal provides "a convenient forum for the expression of responsible geological thought and opinion" and its contributors are not to be limited to members of staff. The present issue, for example, contains a most valuable article by H. R. Hose, of Aluminium Laboratories, Ltd., on "The Geology and Mineral Resources of Jamaica", accompanied by specially prepared geological and mineral maps. A permanent feature of the journal is to be a series of reports of recent progress, contributed by the Surveys themselves. The first batch of eight clearly indicates that for this feature alone the new journal will be widely welcomed. Other sections are devoted to notes on special activities and conferences, discoveries of significance and abstracts of publications ; book reviews; bibliography; personalia; and mineral and metal prices.

The Directorate and the editor, Mr. E. H. Beard (vice-principal of the Mineral Resources Division), are to be congratulated on their enterprise in producing an attractive, authoritative and inexpensive journal which adequately meets a real need and which, apart from its wide appeal to mining engineers, economists and industrialists, will undoubtedly be highly appreciated by geologists, not only in Great Britain and the British Colonies but also throughout the world.

'Colonial Plant and Animal Products, 1, No. 1 (1950). (London: H.M. Stationery Office.) 58. net.

${ }^{3}$ Colonial Geology and Mineral Resources: The Quarterly Bulletin of the Colonial Geological Surveys, 1, No. 1 (1950). Pp. 120. (London: H.M. Stationery Office.) 58 . net.

\section{THE IMPERIAL FORESTRY INSTITUTE, OXFORD}

N October 19, H.R.H. Princess Margaret, in the presence of a large and distinguished gathering, opened the new building of the Department of Forestry of the University of Oxford, on a site in South Parks Road between the Physical Chemistry and Pathology Departments. The Imperial Forestry Institute was founded in 1924 as the outcome of recommendations of the Empire Forestry Conferences of 1920 and 1923, to provide an Empire centre for higher education and research, to be jointly financed by the governments interested and linked with the already existing University School of Forestry. The School owed its origin to arrangements made in 1905 between the University of Oxford and the India Office for the training of probationers for the Indian 